\title{
The Takagi-Sugeno Fuzzy Controller Based Direct Torque Control with Space Vector Modulation for Three-Phase Induction Motor
}

\author{
José Luis Azcue, Alfeu J. Sguarezi Filho and Ernesto Ruppert \\ Additional information is available at the end of the chapter
}

http://dx.doi.org/10.5772/48044

\section{Introduction}

The Direct Torque Control (DTC) has become a popular technique for three-phase Induction Motor (IM) drives because it provides a fast dynamic torque response without the use of current regulators [23][9], however, nowadays exist some other alternative DTC schemes to reduce the torque ripples using the Space Vector Modulation (SVM) technique [11][14]. In general the use of fuzzy systems does not require the accurate mathematic model of the process to be controlled. Instead, it uses the experience and knowledge of the involved professionals to construct its control rule base. Fuzzy logic is powerful in the motor control area, e.g., in [1] the PI and Fuzzy Logic Controllers (FLC) are used to control the load angle which simplifies the IM drive system.

In [8] the FLC is used to obtain the reference voltage vector dynamically in terms of torque error, stator flux error and stator flux angle. In this case both torque and stator flux ripples are remarkably reduced. In [15] the fuzzy PI speed controller has a better response for a wide range of motor speed. Different type of adaptive FLC such as self-tuning and self-organizing controllers has also been developed and implemented in[20][4].

In [18], [13] and [10] are proposed fuzzy systems which outputs are a specific voltage vector numbers, similarly to the classic DTC scheme[23]. On the other hand, in [26] is proposed a fuzzy inference system to modulate the stator voltage vector applied to the induction motor, but it consider the stator current as an additional input.

In [19] two fuzzy controllers are used to generate the two components of the reference voltage vector instead of two PI controllers, similarly, in [7] flux and torque fuzzy controllers are designed to substitute the original flux and torque PI controllers, but these schemes use two independent fuzzy controllers, one for the flux control and another one for the torque control. 
Unlike the schemes mentioned before, the aim of this chapter is to design a Takagi-Sugeno (T-S) Fuzzy controller to substitute flux and torque PI controllers in a conventional DTC-SVM scheme. The T-S fuzzy controller calculates the quadrature components of the stator voltage vector represented in the stator flux reference frame. The rule base for the proposed controller is defined in function of the stator flux error and the electromagnetic torque error using trapezoidal and triangular membership functions. The direct component of the stator voltage takes a linear combination of the inputs as a consequent part of the rules, however, the quadrature component of the stator voltage takes the similar linear combination used in the first output but with the coefficients interchanged, not to be necessary another different coefficients values for this output.

The simulation results shown that the proposed T-S fuzzy controller for the DTC-SVM scheme have a good performance in terms of rise time $\left(t_{r}\right)$, settling time $\left(t_{s}\right)$ and torque ripple when it was tested at different operating conditions validating the proposed scheme. The chapter is organized as follows. In section 2 the direct torque control principles of the DTC for three-phase induction motor is presented. In section 3 the topology of the proposed control scheme is analyzed and in section 4 the proposed T-S fuzzy controller is described in detail mentioning different aspects of its design. Section 5 presents the simulations results of T-S fuzzy controller, and in the end, the conclusion is given in Section 6.

\section{Direct Torque Control principles}

\subsection{Dynamical equations of the three-phase induction motor}

By the definitions of the fluxes, currents and voltages space vectors, the dynamical equations of the three-phase induction motor in stationary reference frame can be put into the following mathematical form [25]:

$$
\begin{aligned}
\vec{u}_{s} & =R_{s} \vec{i}_{s}+\frac{d \vec{\psi}_{s}}{d t} \\
0 & =R_{r} \vec{i}_{r}+\frac{d \vec{\psi}_{r}}{d t}-j \omega_{r} \vec{\psi}_{r} \\
\vec{\psi}_{s} & =L_{s} \vec{i}_{s}+L_{m} \vec{i}_{r} \\
\vec{\psi}_{r} & =L_{r} \vec{i}_{r}+L_{m} \vec{i}_{s}
\end{aligned}
$$

Where $\vec{u}_{s}$ is the stator voltage space vector, $\vec{i}_{s}$ and $\vec{i}_{r}$ are the stator and rotor current space vectors, respectively, $\vec{\psi}_{s}$ and $\vec{\psi}_{r}$ are the stator and rotor flux space vectors, $\omega_{r}$ is the rotor angular speed, $R_{s}$ and $R_{r}$ are the stator and rotor resistances, $L_{s}, L_{r}$ and $L_{m}$ are the stator, rotor and mutual inductance, respectively.

The electromagnetic torque is expressed in terms of the cross-vectorial product of the stator and the rotor flux space vectors.

$$
\begin{aligned}
t_{e} & =\frac{3}{2} P \frac{L_{m}}{L_{r} L_{s} \sigma} \vec{\psi}_{r} \times \vec{\psi}_{s} \\
t_{e} & =\frac{3}{2} P \frac{L_{m}}{L_{r} L_{s} \sigma}\left|\vec{\psi}_{r}\right|\left|\vec{\psi}_{s}\right| \sin (\gamma)
\end{aligned}
$$


Where $\gamma$ is the load angle between stator and rotor flux space vector, $P$ is a number of pole pairs and $\sigma=1-L_{m}^{2} /\left(L_{s} L_{r}\right)$ is the dispersion factor.

The three-phase induction motor model was implemented in MATLAB/Simulink as is shown in [3], the code source of this implementation is shared in MATLAB CENTRAL [2].

\subsection{Direct Torque Control}

In the direct torque control if the sample time is short enough, such that the stator voltage space vector is imposed to the motor keeping the stator flux constant at the reference value. The rotor flux will become constant because it changes slower than the stator flux. The electromagnetic torque (6) can be quickly changed by changing the angle $\gamma$ in the desired direction. This angle $\gamma$ can be easily changed when choosing the appropriate stator voltage space vector.

For simplicity, let us assume that the stator phase ohmic drop could be neglected in (1). Therefore $d \vec{\psi}_{s} / d t=\vec{u}_{s}$. During a short time $\Delta t$, when the voltage space vector is applied it has:

$$
\Delta \vec{\psi}_{s} \approx \vec{u}_{s} \cdot \Delta t
$$

Thus the stator flux space vector moves by $\Delta \vec{\psi}_{s}$ in the direction of the stator voltage space vector at a speed which is proportional to the magnitude of the stator voltage space vector. By selecting step-by-step the appropriate stator voltage vector, it is possible to change the stator flux in the required direction.

\subsubsection{Stator-flux-oriented direct torque control}

The stator-flux-oriented direct torque control (SFO-DTC) based on space vector modulation scheme have two PI controllers as is shown in Fig. 2. This control strategy relies on a simplified description of the stator voltage components expressed in stator-flux-oriented coordinates

$$
\begin{aligned}
& u_{d s}=R_{s} i_{d s}+\frac{d \psi_{s}}{d t} \\
& u_{q s}=R_{s} i_{q s}+\omega_{s} \psi_{s}
\end{aligned}
$$

Therefore, in this reference frame the stator flux quadrature component is zero as is shown in Fig. 1 that means $\psi_{s}=\psi_{d s}$ and $\psi_{q s}=0$. Also, in this reference frame the electromagnetic torque is calculated by

$$
\begin{aligned}
T_{e m} & =\frac{3 P}{2} \psi_{s} i_{q s} \\
i_{q s} & =\frac{2}{3 P} \frac{T_{e m}}{\psi_{s}}
\end{aligned}
$$

However, if the equation (11) is substitute in the equation (9), we can obtain the expression to control the electromagnetic torque applying and appropriate stator voltage quadrature 


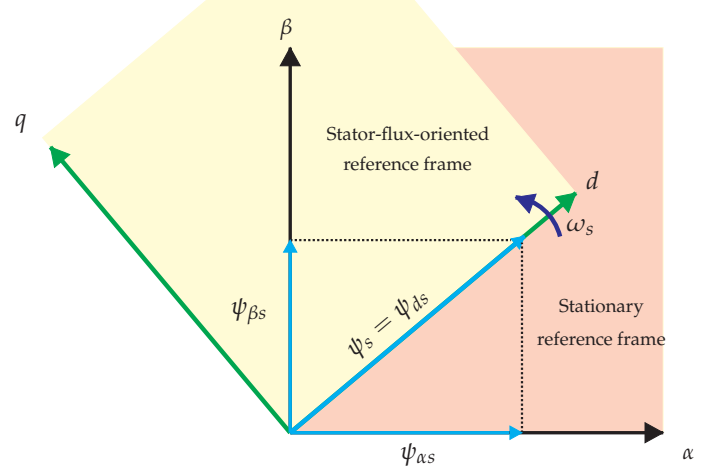

Figure 1. Stator-flux-oriented reference frame.

component, it is:

$$
u_{q s}=\frac{2}{3 P} R_{s} \frac{T_{e m}}{\psi_{s}}+\omega_{s} \psi_{s}
$$

From equation (8), the stator flux is controlled with the stator voltage direct component $u_{d s}$. For every sampled period $T_{S}$, the equation (8) is approximated by

$$
u_{d s}=R_{s} i_{d s}+\Delta \psi_{s} / T_{s}
$$

When the three-phase IM operates at high speeds the term $R_{s} i_{d s}$ can be neglected and the stator voltage can to become proportional to the stator flux change with a switching frequency $1 / T_{s}$. However, at low speeds the term $R_{s} i_{d s}$ is not negligible and with the aim to correct this error is used the PI controller, it is:

$$
u_{d s}^{*}=\left(K_{P \psi}+K_{I \psi} / s\right)\left(\psi_{s}^{*}-\hat{\psi}_{s}\right)
$$

From the equation (12), the electromagnetic torque can be controlled with the stator voltage quadrature component if the term $\omega_{s} \psi_{s}$ is decoupled. A simple form to decoupled it is adding the term $\omega_{s} \psi_{s}$ to the output of the controller as is shown in Fig. 2. Then, the PI controller is used to control the electromagnetic torque, it is:

$$
u_{q s}^{*}=\left(K_{P T_{e m}}+K_{I T_{e m}} / s\right)\left(T_{e m}^{*}-\hat{T}_{e m}\right)+\omega_{s} \psi_{s}
$$

Finally, the outputs of the PI flux and PI torque controllers can be interpreted as the stator voltage components in the stator-flux-oriented coordinates [6].

Where $\omega_{s}$ is the angular speed of the stator flux vector. The equations (12) and (13) show that the component $u_{d s}$ has influence only on the change of stator flux magnitude, and the component $u_{q s}$, if the term $\omega_{s} \psi_{s}$ is decoupled, can be used for torque adjustment. Therefore, after coordinate transformation $d q / \alpha \beta$ into the stationary reference frame, the command values $u_{d s}^{*}, u_{q s}^{*}$ are delivered to SVM. In [3] this scheme is analyzed in detail. 


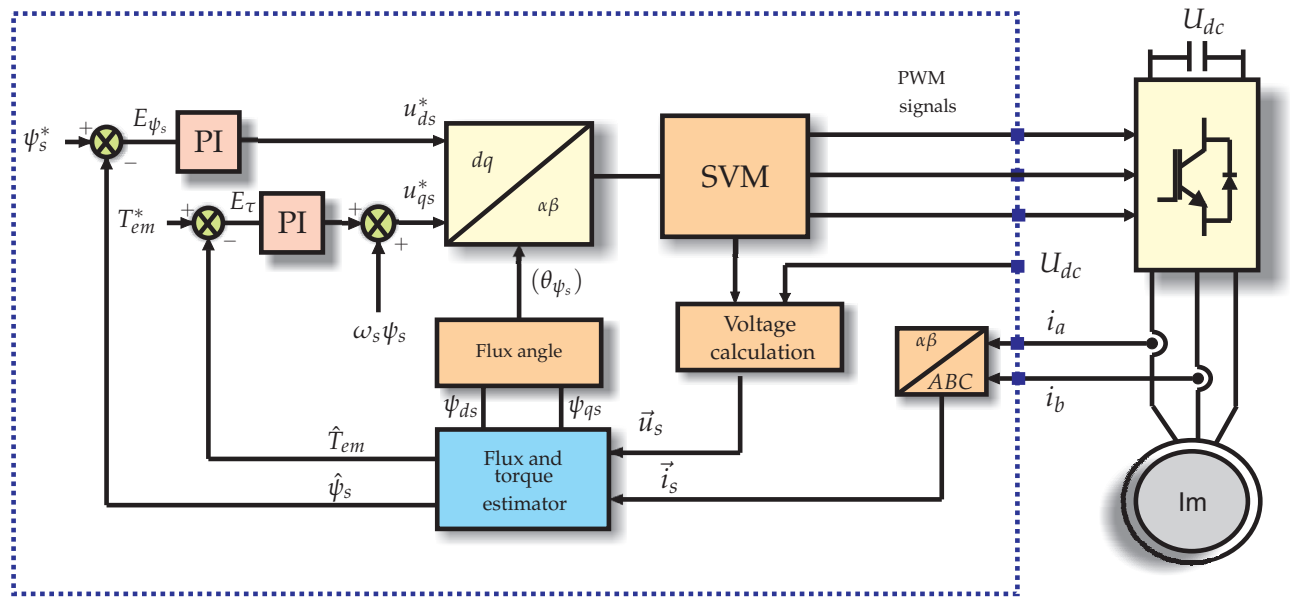

Figure 2. Conventional stator-flux-oriented direct torque control scheme.

The SFO-DTC based on space vector modulation scheme requires the flux and the torque estimators, which can be performed as it is proposed in this chapter, this scheme is used to implement the T-S fuzzy controller proposed.

\section{The proposed direct torque control scheme}

The Figure 3 shows the proposed DTC-SVM scheme, this scheme only needs sense the DC link and the two phases of the stator currents of the three-phase induction motor. In the DTC-SVM scheme the electromagnetic torque error $\left(E_{\tau}\right)$ and the stator flux error $\left(E_{\psi_{s}}\right)$ are the inputs and the stator voltage components are the outputs of the Takagi-Sugeno fuzzy controller, these outputs are represented in the stator flux reference frame. Details about this controller will be presented in the next section.

\subsection{Stator voltage calculation}

The stator voltage calculation use the DC link voltage $\left(\mathbf{U}_{\mathbf{d c}}\right)$ and the inverter switch state $\left(S_{W a}\right.$, $S_{W b}, S_{W c}$ ) of the three-phase two level inverter. The stator voltage vector $\vec{u}_{s}$ is determined as in [5]:

$$
\vec{u}_{s}=\frac{2}{3}\left[\left(S_{W a}-\frac{S_{W b}+S_{W c}}{2}\right)+j \frac{\sqrt{3}}{2}\left(S_{W b}-S_{W c}\right)\right] U_{d c}
$$

\subsection{Space vector modulation technique}

In this work is used the space vector modulation (SVM) technique with the aim to reduce the torque ripple and total harmonic distortion of the current, is therefore necessary to understand the operation and fundamentals that governing their behavior. This concept was discussed in publications such as [24], [12] and [27]. For our purpose the basic ideas are summarized. In Fig. 4 and Fig. 5 are shown the three-phase two level inverter diagram, where the state of the 


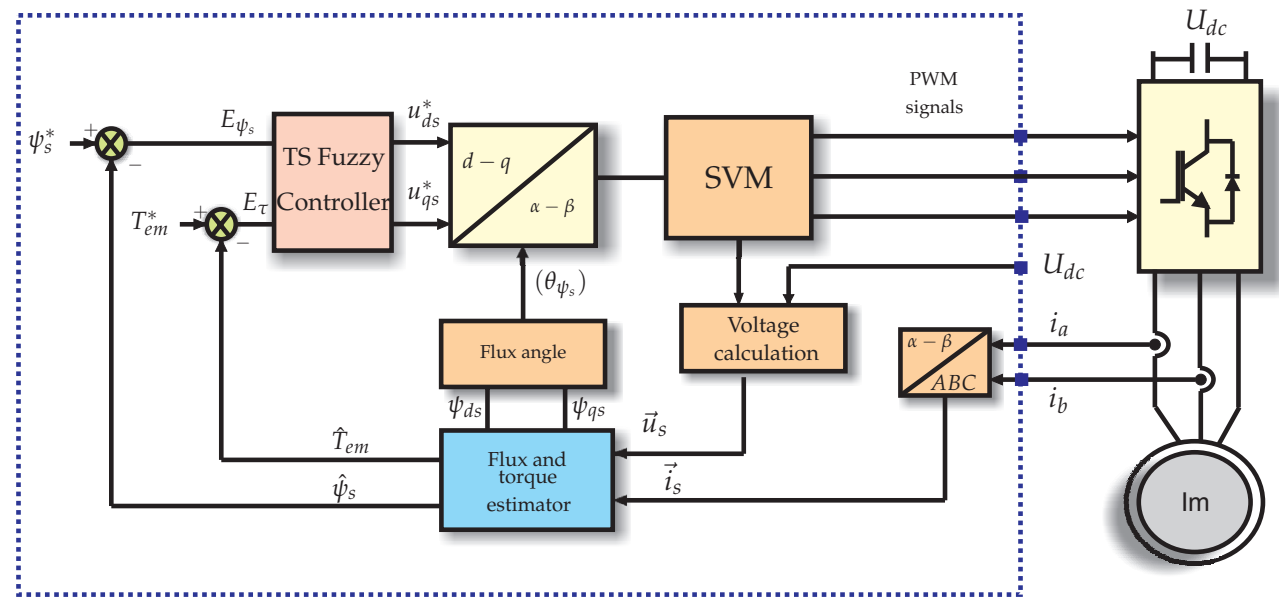

Figure 3. Takagi-Sugeno fuzzy controller in the direct torque control with space vector modulation scheme.

switches follow the following logic.

$$
S_{W i}=\left\{\begin{array}{l}
1, \text { the switch } S_{W i} \text { is ON and the switch } \bar{S}_{W i} \text { is OFF } \\
0, \text { the switch } S_{W i} \text { is OFF and the switch } \bar{S}_{W i} \text { is ON }
\end{array}\right.
$$

Where $\mathrm{i}=\mathrm{a}, \mathrm{b}, \mathrm{c}$ and considering that the switch $\bar{S}_{W i}$ is the complement of $S_{W i}$ is possible to resume all the combinations only considering the top switches as is shown in Table 1.

\begin{tabular}{|c|ccc|}
\hline Vector & $S_{W a}$ & $S_{W b}$ & $S_{W c}$ \\
\hline$\vec{S}_{0}$ & 0 & 0 & 0 \\
$\vec{S}_{1}$ & 1 & 0 & 0 \\
$\vec{S}_{2}$ & 1 & 1 & 0 \\
$\vec{S}_{3}$ & 0 & 1 & 0 \\
$\vec{S}_{4}$ & 0 & 1 & 1 \\
$\vec{S}_{5}$ & 0 & 0 & 1 \\
$\vec{S}_{6}$ & 1 & 0 & 1 \\
$\vec{S}_{7}$ & 1 & 1 & 1 \\
\hline
\end{tabular}

Table 1. Switching vectors

Where $\vec{S}_{0}, \vec{S}_{1}, \vec{S}_{2}, \vec{S}_{3}, \vec{S}_{4}, \vec{S}_{5}, \vec{S}_{6}$ and $\vec{S}_{7}$ are switching vectors. These switching vectors generate six active voltage vectors $\left(\vec{U}_{1}, \vec{U}_{2}, \vec{U}_{3}, \vec{U}_{4}, \vec{U}_{5}\right.$ and $\left.\vec{U}_{6}\right)$ and two zero voltage vectors $\left(\vec{U}_{0}\right.$ and $\left.\vec{U}_{7}\right)$ as are shown in the Figures 6 and 7. The generalized expression to calculate the active and zero voltage vectors is:

$$
\vec{U}_{n}=\left\{\begin{array}{cl}
\frac{2}{3} \sqrt{3} U_{d c} \cdot e^{j(2 n-1) \frac{\pi}{6}}, & n=1, \ldots, 6 \\
0 & , n=0,7
\end{array}\right.
$$

Where $U_{d c}$ is the DC link voltage. 


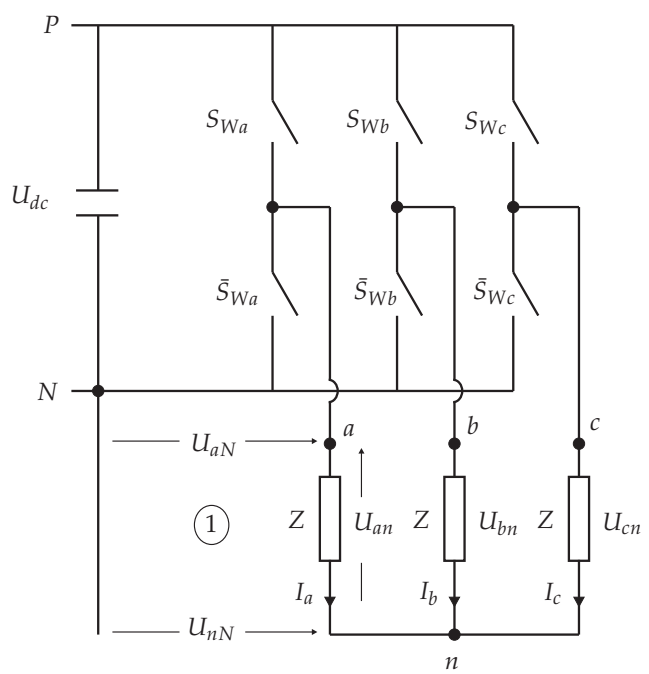

Figure 4. Three-phase two level inverter with load

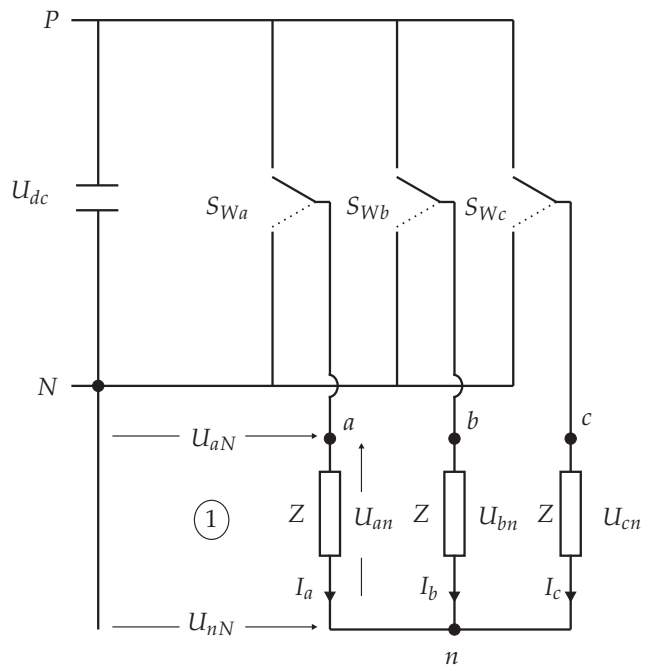

Figure 5. Simplified three-phase two level inverter with load

In Fig. 6 the hexagon is divided in six sectors, and any reference voltage vector is represented as combination of adjacent active and zero voltage vectors, e.g. the voltage vector $\vec{U}^{*}$ is localized in sector I between active vectors $\vec{U}_{1}$ and $\vec{U}_{2}$, as is shown in Fig. 8, and considering a enough short switching period, it is:

$$
\begin{aligned}
\vec{U}^{*} \cdot T_{z} & =\vec{U}_{1} \cdot T_{1}+\vec{U}_{2} \cdot T_{2} \\
\vec{U}^{*} & =\vec{U}_{1} \frac{T_{1}}{T_{z}}+\vec{U}_{2} \frac{T_{2}}{T_{z}}
\end{aligned}
$$




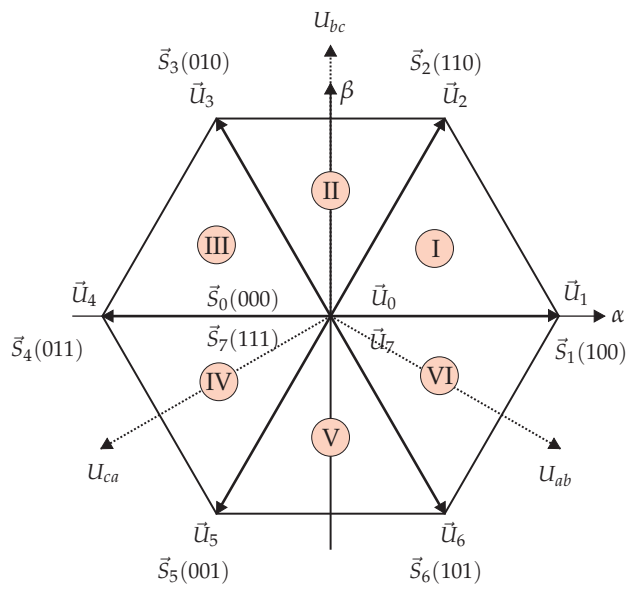

Figure 6. Switching and voltage vectors

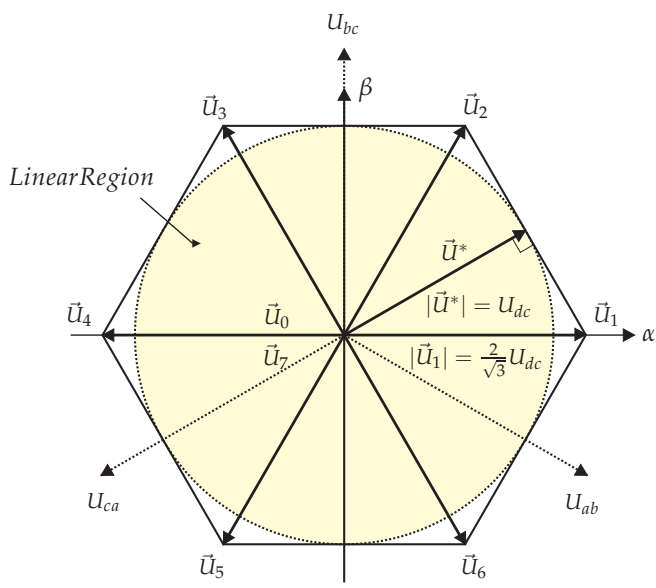

Figure 7. Linear region to work without overmodulation

The times $T_{1}$ and $T_{2}$ are calculated using trigonometric projections as is shown in Fig. 8, it is:

$$
\begin{aligned}
& T_{1}=\frac{\left|\vec{U}^{*}\right|}{\left|\vec{U}_{1}\right|} \cdot T_{z} \frac{\sin \left(\frac{\pi}{3}-\phi\right)}{\sin \left(\frac{2 \pi}{3}\right)} \\
& T_{2}=\frac{\left|\vec{U}^{*}\right|}{\left|\vec{U}_{2}\right|} \cdot T_{z} \frac{\sin (\phi)}{\sin \left(\frac{2 \pi}{3}\right)}
\end{aligned}
$$

Where $T_{1}$ and $T_{2}$ are the times of application of the active vectors in a switching period, $T_{Z}$ is the switching period and $\phi$ is the angle between the reference voltage vector and the adjacent active vector $\left(\vec{U}_{1}\right)$. If the sum of times $T_{1}$ and $T_{2}$ is minor of the switching period, the rest of the time is apply the zero vectors, it is:

$$
T_{0}=T_{7}=T_{Z}-T_{1}-T_{2}
$$




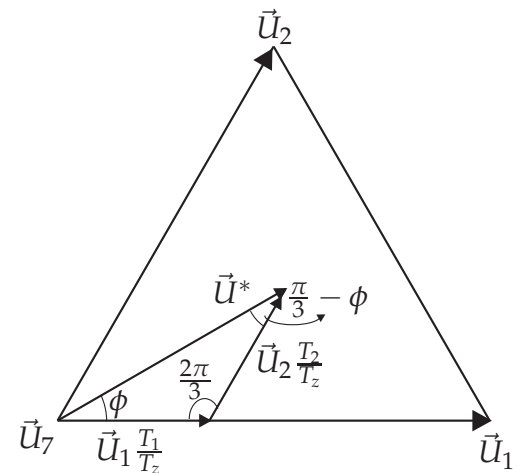

Figure 8. Voltage vector $\vec{U}^{*}$ and its components in sector $I$

Where $T_{0}$ and $T_{7}$ are the times of applications of zero vectors in a switching period. Once calculated the times of applications of each adjacent voltage vectors the next step is to follow a specific switching sequence for the symmetrical space vector modulation technique, this one depends if the reference vector is localized in an even or odd sector, e.g. in Fig. 9 is observed the optimum switching sequence and the pulse pattern for odd sector $\left(\vec{S}_{0}, \vec{S}_{1}, \vec{S}_{2}\right.$ and $\vec{S}_{7}$ ), however for even sector the switching sequence is contrary to the case for odd sector as is shown in Fig. 10.
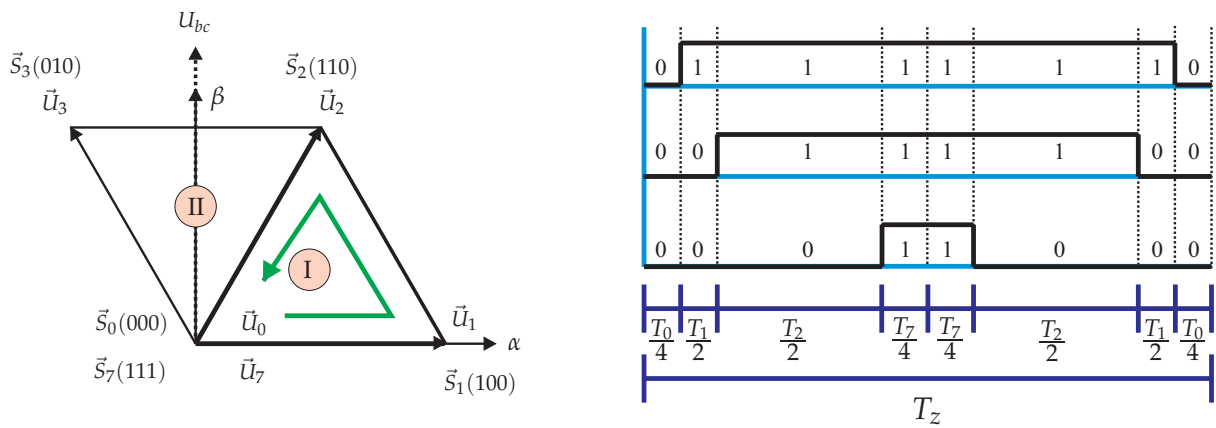

Figure 9. Switching sequence for odd sector.

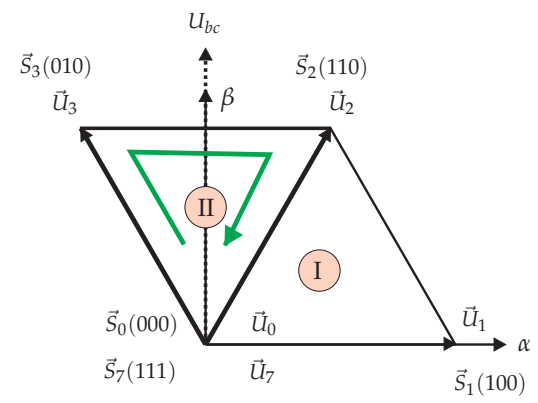

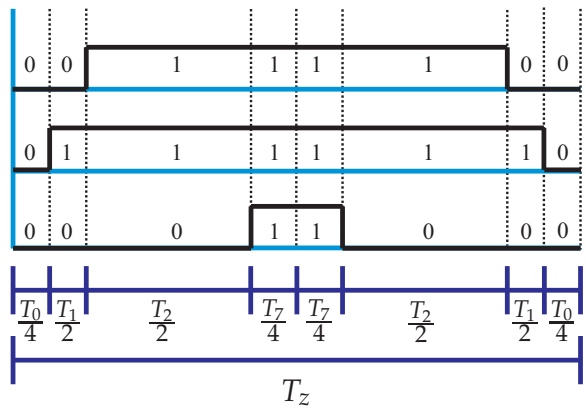

Figure 10. Switching sequence for even sector. 
The details about the implementation of SVM algorithm in MATLAB/Simulink are presented in [3] in page 97.

\subsection{Electromagnetic torque and stator flux estimation}

The Figure 3 shows that the electromagnetic torque and the stator flux estimation depends of the stator voltage and the stator current space vectors, therefore:

$$
\vec{\psi}_{s}=\int\left(\vec{u}_{s}-R_{s} \cdot \vec{i}_{s}\right) d t
$$

The problem in this type of estimation is when in low speeds the back electromotive force (emf) depends strongly of the stator resistance, to resolve this problem is used the current model to improve the flux estimation as in [17]. The rotor flux represented in the rotor flux reference frame is:

$$
\vec{\psi}_{r d q}=\frac{L_{m}}{1+s T_{r}} \vec{i}_{s d q}-j \frac{\left(\omega_{\psi_{r}}-\omega_{r}\right) T_{r}}{1+s T_{r}} \vec{\psi}_{r d q}
$$

Where $T_{r}=L_{r} / R_{r}$ is the rotor time constant. In this reference frame $\psi_{r q}=0$ and substituting this expression in the equation (24), it is:

$$
\psi_{r d}=\frac{L_{m}}{1+s T_{r}} i_{s d}
$$

In the current model the stator flux is represented as:

$$
\vec{\psi}_{s}^{i}=\frac{L_{m}}{L_{r}} \vec{\psi}_{r}^{i}+\frac{L_{s} L_{r}-L_{m}^{2}}{L_{r}} \vec{i}_{s}
$$

Where $\vec{\psi}_{r}^{i}$ is the rotor flux estimated in the equation (25). The voltage model is based in the equation (1) and from there the stator flux in the stationary reference frame is:

$$
\vec{\psi}_{s}=\frac{1}{S}\left(\vec{v}_{S}-R_{s} \vec{i}_{S}-\vec{U}_{c o m p}\right)
$$

With the aim to correct the errors associated with the pure integration and the stator resistance variations with temperature, the voltage model is adapted through the PI controller.

$$
\vec{U}_{c o m p}=\left(K_{p}+K_{i} \frac{1}{s}\right)\left(\vec{\psi}_{s}-\vec{\psi}_{s}^{i}\right)
$$

The $K_{p}$ and $K_{i}$ coefficients are calculated with the recommendation proposed in [17]. The rotor flux $\vec{\psi}_{r}$ in the stationary reference frame is calculated as:

$$
\vec{\psi}_{r}=\frac{L_{r}}{L_{m}} \vec{\psi}_{s}-\frac{L_{s} L_{r}-L_{m}^{2}}{L_{m}} \vec{i}_{s}
$$

The estimator scheme shown in the Figure 11 works with a good performance in the wide range of speeds. 


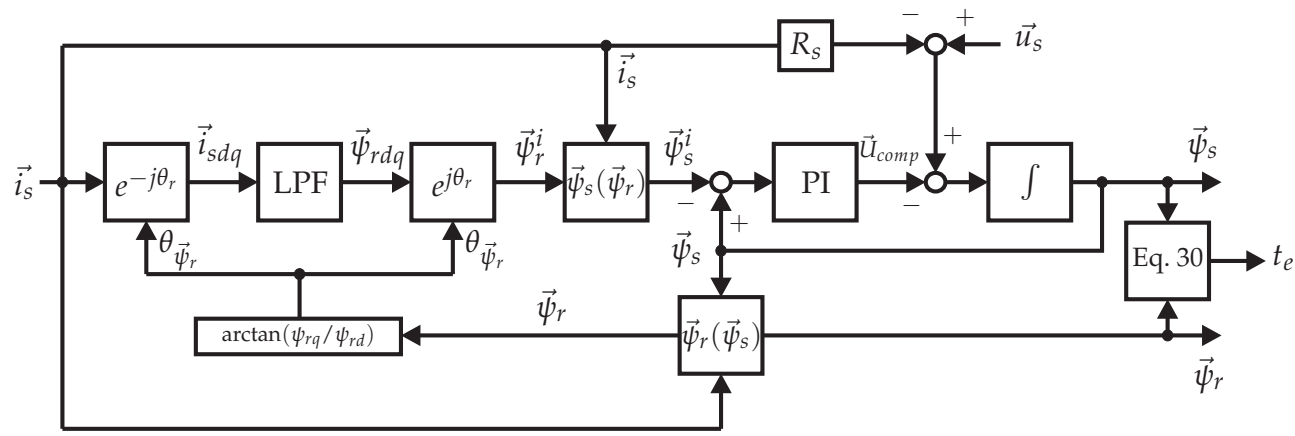

Figure 11. Stator and rotor flux estimator, and electromagnetic torque estimator.

Where LPF means low pass filter. In the other hand, when the equations (27) and (29) are replaced in (5) it is estimated the electromagnetic torque.

$$
t_{e}=\frac{3}{2} P \frac{L_{m}}{L_{r} L_{s} \sigma} \vec{\psi}_{r} \times \vec{\psi}_{s}
$$

\section{Design of Takagi-Sugeno fuzzy controller}

The Takagi-Sugeno Fuzzy controller takes as inputs the stator flux error $E_{\psi_{s}}$ and the electromagnetic torque error $E_{\tau}$, and as outputs the quadrature components of the stator voltage vector, represented in the stator flux reference frame. The first output $\left(u_{d s}^{*}\right)$ takes a linear combination of the inputs as a consequent part of the rules, similarly, the second output $\left(u_{q S}^{*}\right)$ takes the similar linear combination used in the first output but with the coefficients interchanged how is shown in the Figure 12.

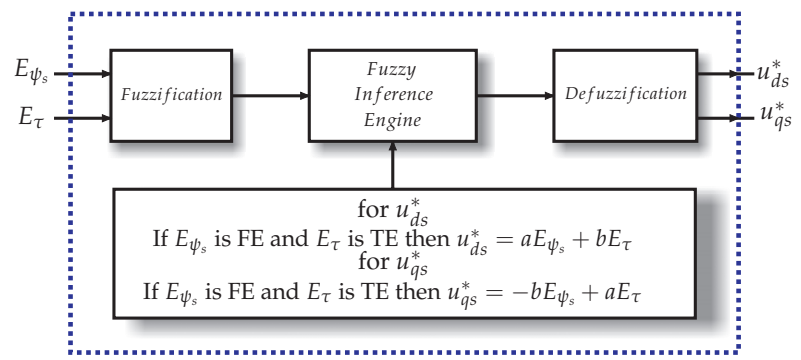

Figure 12. The structure of a fuzzy logic controller.

\subsection{Membership functions}

The Membership Functions (MF) for T-S fuzzy controller are shown in Figure 13 and in Figure 14, for the stator flux error and the electromagnetic torque error, respectively. These MF's shape and parameters was found through trial and error method with multiple simulations and with the knowing of the induction motor response for every test. This method is know as subjective approach [22]. 
The universe of discourse for the stator flux error input is defined in the closed interval [-0.5, 0.5]. The extreme MFs have trapezoidal shapes but the middle one takes triangular shape as is shown in Figure 13. However, the universe of discourse for electromagnetic torque error input is defined in the closed interval $[-20,20]$ but with the objective to see the shape of the MFs only is shown the interval $[-5,5]$ in Figure 14, the shapes of these MF are similar to the first input. For both inputs the linguistic labels N, Ze and P means Negative, Zero and Positive, respectively.

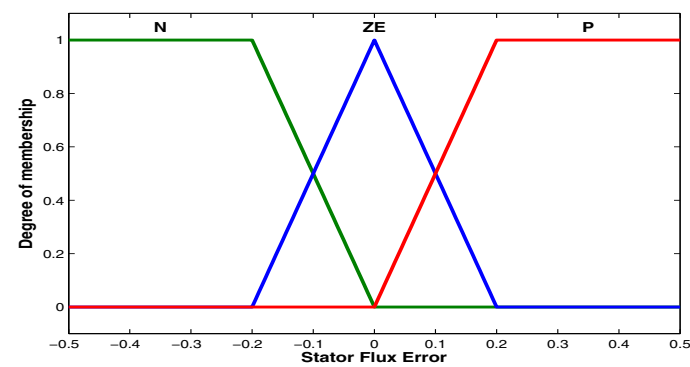

Figure 13. Membership function for stator flux error input $\left(E_{\psi_{s}}\right)$

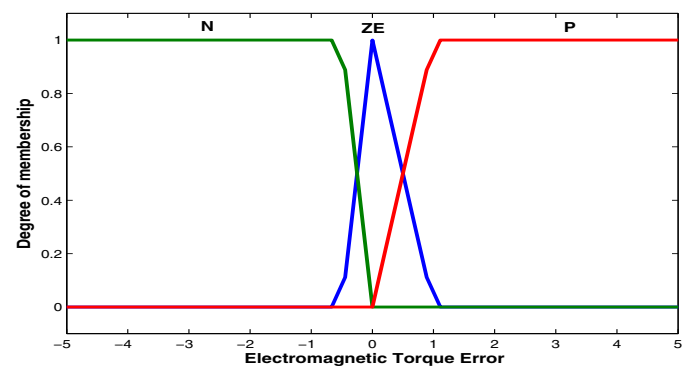

Figure 14. Membership function for electromagnetic torque error input $\left(E_{\tau}\right)$

\subsection{The fuzzy rule base}

The direct component of the stator voltage $u_{d s}^{*}$ is determined by the rules of the form:

$$
R_{x}: \text { if } E_{\psi_{s}} \text { is } F E \text { and } E_{\tau} \text { is } T E \text { then } u_{d s}^{*}=a E_{\psi_{s}}+b E_{\tau}
$$

However, the quadrature component of the stator voltage $u_{q s}^{*}$ is determined by the rules of the form:

$$
R_{y}: \text { if } E_{\psi_{s}} \text { is } F E \text { and } E_{\tau} \text { is } T E \text { then } u_{q s}^{*}=-b E_{\psi_{s}}+a E_{\tau}
$$

Where $F E=T E=\{N, Z E, P\}$ are the fuzzy sets of the inputs and, $\mathbf{a}$ and $\mathbf{b}$ are coefficients of the first-order polynomial function typically present in the consequent part of the firs-order Takagi-Sugeno fuzzy controllers. 
For instance, when the consequent function of the rule $R_{i}$ is a real number, the consequent function is a zero-order polynomial and we have a zero-order controller. If the consequent function is a linear we have first-order controller [21].

$$
R_{i}: \text { if } X \text { is } A_{i} \text { and } Y \text { is } B_{i} \text { then } z=f_{i}(X, Y)
$$

The rule base to calculate $u_{d s}^{*}$ and $u_{q s}^{*}$ is shown in Table 2. The product is the conjunction operator and the weighted average (wtaver) is the defuzzification method used to set the controller in the MATLAB fuzzy editor.

\begin{tabular}{c|lll}
\hline $\mathbf{E}_{-\mathrm{s}} / \mathbf{E}_{\boldsymbol{\theta}}$ & $\mathbf{N}$ & $\mathbf{Z E}$ & $\mathbf{P}$ \\
\hline $\mathbf{N}$ & $u_{d s}^{*}=a F_{e}+b T_{e}$ & $u_{d s}^{*}=a F_{e}+b T_{e}$ & $u_{d s}^{*}=a F_{e}+b T_{e}$ \\
& $u_{q s}^{*}=-b F_{e}+a T_{e}$ & $u_{q s}^{*}=-b F_{e}+a T_{e}$ & $u_{q s}^{*}=-b F_{e}+a T_{e}$ \\
\hline $\mathbf{Z E}$ & $u_{d s}^{*}=a F_{e}+b T_{e}$ & $u_{d s}^{*}=a F_{e}+b T_{e}$ & $u_{d s}^{*}=a F_{e}+b T_{e}$ \\
& $u_{q s}^{*}=-b F_{e}+a T_{e}$ & $u_{q s}^{*}=-b F_{e}+a T_{e}$ & $u_{q s}^{*}=-b F_{e}+a T_{e}$ \\
\hline $\mathbf{P}$ & $u_{d s}^{*}=a F_{e}+b T_{e}$ & $u_{d s}^{*}=a F_{e}+b T_{e}$ & $u_{d s}^{*}=a F_{e}+b T_{e}$ \\
& $u_{q s}^{*}=-b F_{e}+a T_{e}$ & $u_{q s}^{*}=-b F_{e}+a T_{e}$ & $u_{q s}^{*}=-b F_{e}+a T_{e}$ \\
\hline
\end{tabular}

Table 2. Fuzzy rules for computation of $u_{d s}^{*}$ and $u_{q s}^{*}$

\section{Simulation results}

The simulations were performed using MATLAB simulation package which include Simulink block sets and fuzzy logic toolbox. The switching frequency of PWM inverter was set to be $10 \mathrm{kHz}$, the stator reference flux considered was $0.47 \mathrm{~Wb}$ and the coefficients considered were $a=90$ and $b=2$. In order to investigate the effectiveness of the proposed control system and in order to check the closed-loop stability of the complete system, we performed several tests.

We used different dynamic operating conditions such as: step change in the motor load (from 0 to $1.0 \mathrm{pu}$ ) at fifty percent of rated speed, no-load sudden change in the speed reference (from $0.5 \mathrm{pu}$ to $-0.5 \mathrm{pu}$ ), and the application of an arbitrary load torque profile at fifty percent of rated speed. The motor parameters are given in Table 3.

\begin{tabular}{|l||c|}
\hline Rated voltage $(\mathrm{V})$ & $220 / 60 \mathrm{~Hz}$ \\
\hline Rated Power $(\mathrm{HP})$ & 3 \\
\hline Rated Torque $(\mathrm{Nm})$ & 11.9 \\
\hline Rated Speed $(\mathrm{rad} / \mathrm{s})$ & 179 \\
\hline$R_{s}, R_{r}(\Omega)$ & $0.435,0.816$ \\
\hline$L_{l s}, L_{l r}(\mathrm{H})$ & $0.002,0.002$ \\
\hline$L_{m}(\mathrm{H})$ & 0.0693 \\
\hline$J\left(K_{g} m^{2}\right)$ & 0.089 \\
\hline $\mathrm{P}($ pole pairs $)$ & 2 \\
\hline
\end{tabular}

Table 3. Induction Motor Parameters [16]

The Figure 15 illustrates the torque response of the DTC-SVM scheme with T-S fuzzy controller when the step change in the motor load is apply. The electromagnetic torque tracked the reference torque and in this test is obtained the following good performance measures: rise time $t_{r}=1.1 \mathrm{~ms}$, settling time $t_{s}=2.2 \mathrm{~ms}$ and torque ripple ripple $=2.93 \%$. Also is observed that the behavior of the stator current is sinusoidal. 

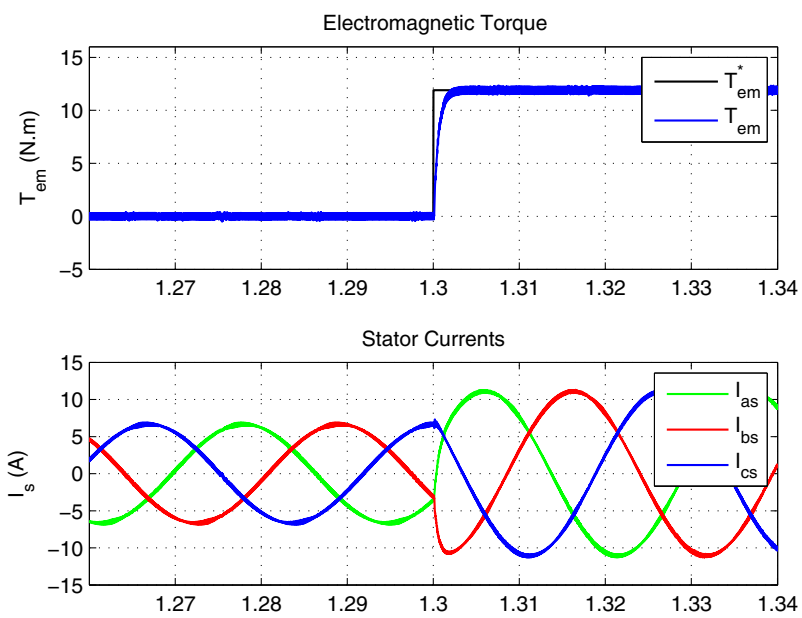

Figure 15. Electromagnetic torque and stator current response for step change in the motor load at fifty percent of rated speed

The Figure 16 presents the results when an arbitrary torque profile is imposed to DTC-SVM scheme with T-S fuzzy controller. In the first sub-figure the electromagnetic torque tracked the reference torque as expected, and in the next one the sinusoidal waveforms of the stator currents is shown. The Figure 17 shows space of the quadrature components of the stator flux and it shows the circular behavior of the stator flux when the torque profile is applied, and in consequence the proposed controller maintain the stator flux constant.
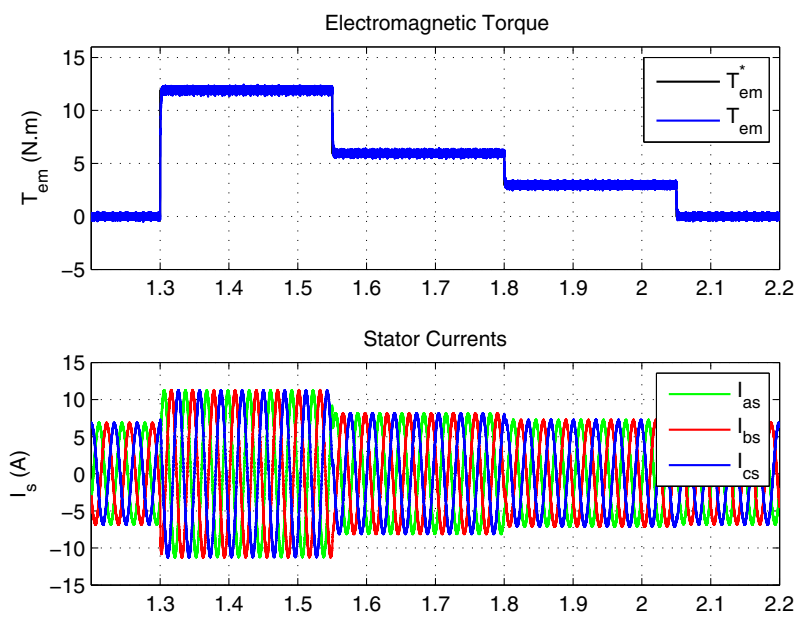

Figure 16. Electromagnetic torque and stator current response when is apply the load torque profile at fifty percent of rated speed 


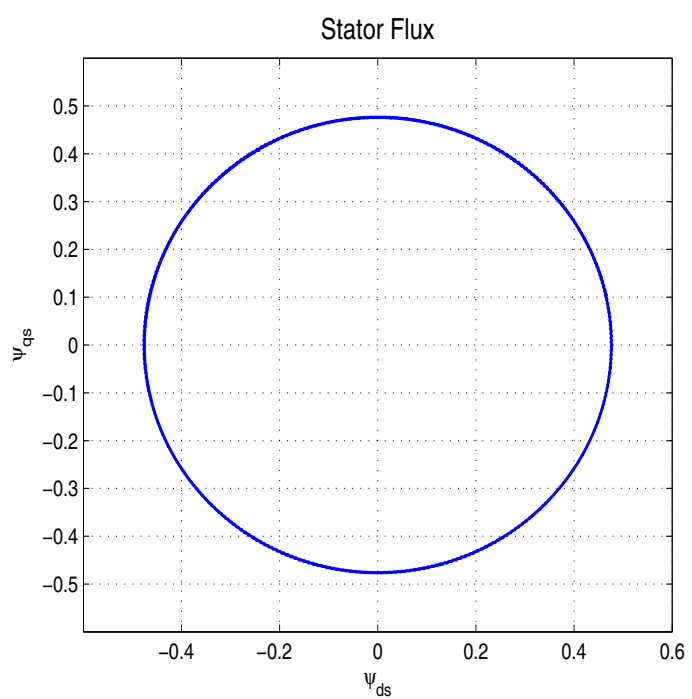

Figure 17. Space of the stator flux quadrature components.

The Figure 18 shows the behavior of the rotor angular speed $\omega_{r}$, the electromagnetic torque and the phase a stator current waveform when a step change in the reference speed from $0.5 \mathrm{pu}$ to $-0.5 \mathrm{pu}$ is imposed, with no-load. The torque was limited in 1.5 times the rated torque how it was projected and the sinusoidal waveforms of the stator current shown that this control technique allowed also a good current control because it is inherent to the algorithm control
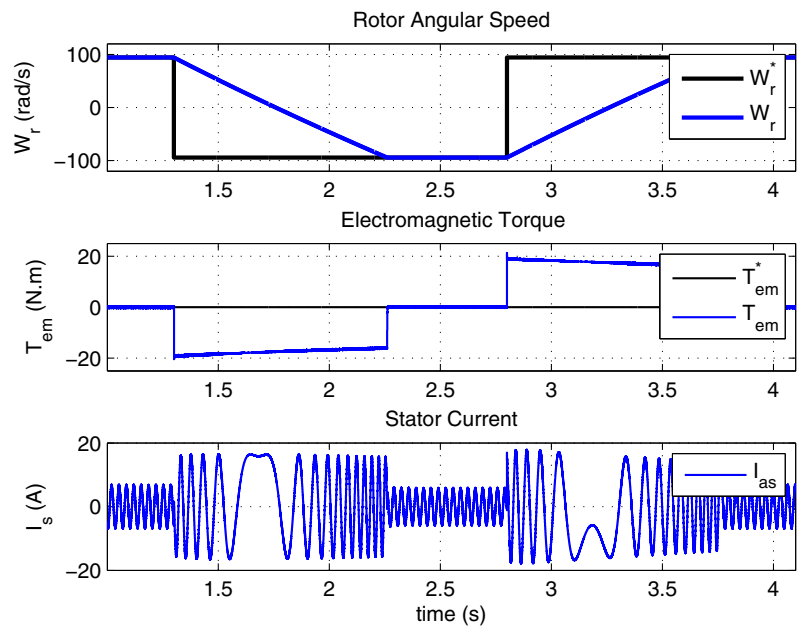

Figure 18. Rotor angular speed, electromagnetic torque and phase a stator current when was apply the no-load sudden change in the speed reference at fifty percent of rated speed 
proposed in this chapter. All the test results showed the good performance of the proposed DTC-SVM scheme with T-S fuzzy controller.

\section{Conclusion}

This chapter presents the DTC-SVM scheme with T-S fuzzy controller for the three-phase IM. The conventional DTC-SVM scheme takes two PI controllers to generate the reference stator voltage vector. To improve the drawback of this conventional DTC-SVM scheme is proposed the Takagi-Sugeno fuzzy controller to substitute both PI controllers. The proposed controller calculates the quadrature components of the reference stator voltage vector in the stator flux reference frame. The rule base for the proposed controller is defined in function of the stator flux error and the electromagnetic torque error using trapezoidal and triangular membership functions. The direct component of the stator voltage takes a linear combination of its inputs as a consequent part of the rules, however, the quadrature component of the stator voltage takes the similar linear combination used in the first output but with the coefficients interchanged, not to be necessary another different coefficients values for this output. Constant switching frequency and low torque ripple are obtained using space vector modulation technique.

Simulations at different operating conditions have been carried out. The simulation results verify that the proposed DTC-SVM scheme with T-S fuzzy controller achieved good performance measures such as rise time, settling time and torque ripple as expected, It shown the fast torque response and low torque ripple in a wide range of operating conditions such as step change in the motor load, no-load sudden change in the speed reference, and the application of an arbitrary load torque profile. These results validate the proposed scheme.

\section{Author details}

José Luis Azcue and Ernesto Ruppert

University of Campinas (UNICAMP), Brazil

Alfeu J. Sguarezi Filho

CECS/UFABC, Santo André - SP, Brazil

\section{References}

[1] Abu-Rub, H., Guzinski, J., Krzeminski, Z. \& Toliyat, H. [2004]. Advanced control of induction motor based on load angle estimation, Industrial Electronics, IEEE Transactions on 51(1): $5-14$.

[2] Azcue P., J. L. [2009]. Modelamento e simulação do motor de indução trifásico. URL:http://wwww.mathworks.fr/matlabcentral/fileexchange/24403-modelamento-e-simulação-domotor-de-indução-trifásico

[3] Azcue P., J. L. [2010]. Three-phase induction motor direct torque control using self-tuning pi-type type fuzzy controller., Master's thesis, University of Campinas (UNICAMP). URL: http://cutter.unicamp.br/document/?code $=000777279$ 
[4] Azcue P., J. \& Ruppert, E. [2010]. Three-phase induction motor dtc-svm scheme with self-tuning pi-type fuzzy controller, Fuzzy Systems and Knowledge Discovery (FSKD), 2010 Seventh International Conference on, Vol. 2, pp. $757-762$.

[5] Bertoluzzo, M., Buja, G. \& Menis, R. [2007]. A direct torque control scheme for induction motor drives using the current model flux estimation, Diagnostics for Electric Machines, Power Electronics and Drives, 2007. SDEMPED 2007. IEEE International Symposium on pp. $185-190$.

[6] Buja, G. \& Kazmierkowski, M. [2004]. Direct torque control of pwm inverter-fed ac motors - a survey, Industrial Electronics, IEEE Transactions on 51(4): 744-757.

[7] Cao, S., Liu, G. \& Cai, B. [2009]. Direct torque control of induction motors based on double-fuzzy space vector modulation technology, Information Engineering and Computer Science, 2009. ICIECS 2009. International Conference on, pp. 1 -4.

[8] Chen, L., Fang, K.-L. \& Hu, Z.-F. [2005]. A scheme of fuzzy direct torque control for induction machine, Machine Learning and Cybernetics, 2005. Proceedings of 2005 International Conference on, Vol. 2, pp. $803-807$ Vol. 2.

[9] Depenbrock, M. [1988]. Direct self-control (dsc) of inverter-fed induction machine, Power Electronics, IEEE Transactions on 3(4): $420-429$.

[10] Ding, X., Liu, Q., Ma, X., He, X. \& Hu, Q. [2007]. The fuzzy direct torque control of induction motor based on space vector modulation, Natural Computation, 2007. ICNC 2007. Third International Conference on, Vol. 4, pp. 260 -264.

[11] Habetler, T., Profumo, F., Pastorelli, M. \& Tolbert, L. [1992]. Direct torque control of induction machines using space vector modulation, Industry Applications, IEEE Transactions on 28(5): $1045-1053$.

[12] Holtz, J. [1992]. Pulsewidth modulation-a survey, Industrial Electronics, IEEE Transactions on 39(5): $410-420$.

[13] Jiang, Z., Hu, S. \& Cao, W. [2008]. A new fuzzy logic torque control scheme based on vector control and direct torque control for induction machine, Innovative Computing Information and Control, 2008. ICICIC '08. 3rd International Conference on, p. 500.

[14] Kang, J.-K. \& Sul, S.-K. [1999]. New direct torque control of induction motor for minimum torque ripple and constant switching frequency, Industry Applications, IEEE Transactions on 35(5): $1076-1082$.

[15] Koutsogiannis, Z., Adamidis, G. \& Fyntanakis, A. [2007]. Direct torque control using space vector modulation and dynamic performance of the drive, via a fuzzy logic controller for speed regulation, Power Electronics and Applications, 2007 European Conference on, pp. $1-10$.

[16] Krause, P. C., Wasynczuk, O. \& Sudhoff, S. D. [2002]. Analysis of Electric Machinery and Drive Systems, IEEE Press.

[17] Lascu, C., Boldea, I. \& Blaabjerg, F. [2000]. A modified direct torque control for induction motor sensorless drive, Industry Applications, IEEE Transactions on 36(1): 122-130.

[18] Lin, G. \& Xu, Z. [2010]. Direct torque control of induction motor based on fuzzy logic, Computer Engineering and Technology (ICCET), 2010 2nd International Conference on, Vol. 4, pp. V4-651 -V4-654.

[19] Pan, Y. \& Zhang, Y. [2009]. Research on direct torque control of induction motor based on dual-fuzzy space vector modulation technology, Fuzzy Systems and Knowledge Discovery, 2009. FSKD '09. Sixth International Conference on, Vol. 6, pp. 383 -388. 
[20] Park, Y.-M., Moon, U.-C. \& Lee, K. [1995]. A self-organizing fuzzy logic controller for dynamic systems using a fuzzy auto-regressive moving average (farma) model, Fuzzy Systems, IEEE Transactions on 3(1): $75-82$.

[21] Pedrycz, W. \& Gomide, F. [2007]. Fuzzy Systems Engineering Toward Human-Centric Computing, Wiley-IEEE Press.

[22] Reznik, L. [1997]. Fuzzy Controllers Handbook: How to Design Them, How They Work, Newnes.

[23] Takahashi, I. \& Noguchi, T. [1986]. A new quick-response and high-efficiency control strategy of an induction motor, Industry Applications, IEEE Transactions on IA-22(5): 820 $-827$.

[24] van der Broeck, H., Skudelny, H. \& Stanke, G. [1988]. Analysis and realization of a pulsewidth modulator based on voltage space vectors, Industry Applications, IEEE Transactions on 24(1): 142-150.

[25] Vas, P. [1998]. Sensorless vector and Direct Torque Control, Oxford University Press.

[26] Viola, J., Restrepo, J., Guzman, V. \& Gimenez, M. [2006]. Direct torque control of induction motors using a fuzzy inference system for reduced ripple torque and current limitation, Power Electronics and Motion Control Conference, 2006. EPE-PEMC 2006. 12th International, pp. $1161-1166$.

[27] Zhou, K. \& Wang, D. [2002]. Relationship between space-vector modulation and three-phase carrier-based PWM: a comprehensive analysis [three-phase inverters], Industrial Electronics, IEEE Transactions on 49(1): 186-196. 